\title{
LATENT CLASS CLUSTER ANALYSIS UNTUK PENGELOMPOKAN KABUPATEN/KOTA DI PROVINSI JAWA TENGAH BERDASARKAN INDIKATOR INDEKS PEMBANGUNAN MANUSIA 2017
}

\section{Latent Class Cluster Analysis for Grouping of Districts/Cities in Central Java province Based on Human Development Index Indicators 2017}

\author{
Atika Nurani Ambarwati \\ Akademi Statistika Muhammadiyah Semarang \\ Jalan Prof. Dr. Hamka Km. 01 Ngalian, Tambak Aji, Kota Semarang, 50815, Jawa Tengah, Indonesia \\ e-mail: atika.nurani@gmail.com
}

\begin{abstract}
Abstrak: Pembangunan merupakan salah satu upaya untuk meningkatkan kesejahteraan dan kemakmuran masyarakat, dengan kedudukan manusia menjadi topik sentra dalam tiap perolehan program pembangunan. Keberhasilan pembangunan suatu bangsa ditentukan oleh ketersediaan Sumber Daya Manusia (SDM) yang berkualitas. Untuk mengukur suatu keberhasilan pembangunan manusia suatu bangsa salah satu indikator yang digunakan adalah Indeks Pembangun Manusia (IPM). IPM di Provinsi Jawa Tengah mengalami peningkatan setiap tahunnya. Pada tahun 2017 pembangunan manusia di Provinsi Jawa Tengah mengalami kenaikan status dari status "sedang" menjadi status "tinggi" yaitu sebesar 70,52 persen. Salah satu permasalahan pembangunan di Jawa Tengah adalah tinggi rendahnya Indeks Pembangunan Manusia (IPM) hanya ditunjukkan melalui indeks komposit, tetapi tidak ditunjukkan indikator mana yang dominan terhadap tinggi rendahnya peringkat Indeks Pembangunan Manusia (IPM). Maka pengelompokan dan pengklasifikasian wilayah kabupaten/kota di Provinsi Jawa Tengah perlu dilakukan sehingga dapat menunjukkan indikator mana yang dominan terhadap tinggi rendahnya peringkat IPM. Latent Class Cluster Analysis merupakan salah satu metode untuk mengklasifikasikan kabupaten/kota. Hasil dari penelitian mendapatkan 2 kelompok. Kelompok pertama terdiri dari kabupaten atau kota yang memiliki pembangunan manusia rendah. Kelompok kedua terdiri dari kabupaten atau kota yang memiliki pembangunan manusia tinggi.
\end{abstract}

Kata Kunci: Indeks Pembangunan Manusia, Indikator Indeks Pembangunan Manusia, Latent Class Cluster Analysis

\begin{abstract}
Development is one of the efforts to improve the welfare and prosperity of the community, with the position of humans being the center of the topic in the acquisition of development programs. The success of a nation's development is determined by the availability of quality Human Resources (HR). To measure the success of a nation's human development one of the indicators used is the Human Builder Index (HDI). HDI in Central Java Province has increased every year. In 2017 human development in Central Java Province has increased from "medium" to "high" status, which is 70.52 percent. One of the development problems in Central Java is the high and low of the Human Development Index (HDI) only shown through the composite index, but it does not indicate which indicators are dominant against the high or low ranking of the Human Development Index (HDI). Then the grouping and classification of regency / city areas in Central Java Province needs to be done so that it can show which indicators are dominant against the high and low HDI ratings. Latent Class Cluster Analysis is one method for classifying districts / cities. The results of the study found 2 groups. The first group consists of districts or cities that have low human development. The second group consists of districts or cities that have high human development.
\end{abstract}

Keywords: Human Development Index, Human Development Index Indicator, Latent Class Cluster Analysis 


\section{PENDAHULUAN}

Pembangunan merupakan salah satu upaya untuk meningkatkan kesejahteraan dan kemakmuran masyarakat [1]. Pembangunan harus dilakukan secara sistematis dan berkesinambungan sesuai preferensi dan kebutuhan masing-masing daerah dengan dasar dan tujuan pembangunan nasional yang telah ditetapkan melalui pembangunan jangka pendek dan jangka panjang [2]. Pembangunan nasional dilakukan secara berkelanjutan dengan landasan kemampuan nasional dengan memanfaatkan kemajuan ilmu pengetahuan dan teknologi serta memperhatikan tantangan perkembangan global guna meningkatkan kualitas manusia dan masyarakat Indonesia [3].

Kedudukan manusia menjadi topik sentra dalam tiap program perolehan pembangunan. Pembangunan manusia didefinisikan sebagai proses untuk pengembangan pilihan yang lebih banyak kepada penduduk melalui upaya pemberdayaan yang memprioritaskan pada peningkatan kemampuan dasar manusia agar dapat sepenuhnya ikut serta diseluruh bidang pembangunan [4]. Keberhasilan pembangunan suatu bangsa ditentukan oleh ketersediaan Sumber Daya Manusia (SDM) yang berkualitas, yaitu SDM yang memiliki fisik tangguh, mental yang kuat, kesehatan yang prima serta memiliki akal yang cerdas [5]. Untuk mengukur suatu keberhasilan pembangunan salah satu indikator yang bisa digunakan adalah Indeks Pembangunan Manusia (IPM) [1].

IPM merupakan suatu indeks komposit yang meliputi tiga aspek pembangunan manusia yang dianggap sangat mendasar yang dilihat dari segi kualitas fisik dan non fisik penduduk [2]. Tiga aspek pokok pembangunan manusia diantaranya aspek kesehatan, aspek pengetahuan dan aspek pengetahuan. Aspek pembangunan manusia memiliki standar pengukurannya dari aspek kesehatan menggunakan angka harapan hidup waktu lahir, dari aspek pengetahuan menggunakan rata-rata lama sekolah dan harapan lama sekolah, dari aspek kehidupan yang layak menggunakan kemampuan daya beli masyarakat terhadap sejumlah kebutuhan pangan dan non pangan [6]. IPM ini ditetapkan oleh PBB secara umum agar dapat dipergunakan untuk membandingkan antar daerah atau antar negara [7].

IPM di Indonesia terus mengalami peningkatan setiap tahunnya, pada periode 2008-2012 menempati urutan keempat diantara sebelas negara-negara anggota ASEAN, IPM tertinggi di dua negara yaitu Singapura dan Brunei Darussalam [8]. Pada tahun 2008 IPM Indonesia mengalami penurunan, hal ini disebabkan oleh krisis ekonomi yang di mulai tahun 1997, sedangkan peningkatan IPM Indonesia pada tahun 2009 diduga karena pengaruh desentralisasi pemerintahan [9]. Pada periode 2010-2015 IPM Indonesia terus mengalami kemajuan, IPM Indonesia meningkat dari 66,53 persen pada tahun 2010 menjadi 69,55 persen pada tahun 2015, IPM Indonesia rata-rata tumbuh sebesar 0,91\% per tahun, meskipun selama periode 2010-2015 IPM Indonesia mengalami kemajuan yang besar, namun status pembangunan manusia Indonesia masih stagnan berstatus "sedang" [10].

Pada Tahun 2016, IPM Indonesia telah mencapai 70,18 persen, Angka ini meningkat sebesar 0,63 persen dibanding dengan IPM Indonesia pada tahun 2015, Selama periode 2010-2016, IPM Indonesia mengalami peningkatan yang tinggi, status pembangunan manusia di Indonesia mengalami peningkatan dari yang berstatus "sedang" menjadi "tinggi" [11]. Pada tahun 2017 IPM Indonesia mencapai 70,81 persen meningkat sebesar 0,90\% dibanding tahun 2016 [12]. Namun IPM di 33 provinsi di Indonesia masih mengalami perbedaan signifikan, Provinsi Papua yang merupakan wilayah paling timur di Indonesia memiliki IPM dengan angka terkecil yaitu 60-65 persen, dan 21 provinsi lainnya termasuk Jawa Tengah memiliki range IPM dikisaran 70-75 persen, sedangkan range IPM tertinggi berkisar 75-80 persen terdapat 8 provinsi. Pada tahun 2006 sampai dengan 2008 IPM pada kabupaten/kota di Provinsi Jawa Tengah mengalami fluktuasi setiap tahunnya terutama di Kabupaten Tegal, sedangkan kabupaten/kota lainnya mengalami peningkatan selama tahun 2006 sampai dengan 2008, kemudian sedikit meningkat pada tahun 2009 [9].

Pada tahun 2010 IPM Jawa Tengah meningkat dari 66,08 persen menjadi 69,49 persen pada tahun 2015, selama periode tersebut, IPM Jawa Tengah rata-rata tumbuh sebesar 1,03\% per tahun, Provinsi Jawa Tengah pada tahun 2012 menempati peringkat 15, secara nasional dengan nilai 73,36 persen, angka ini naik 0,42 dari tahun sebelumnya yang berada di angka 72,94 persen [13]. Pada periode 2014-2015 IPM Jawa Tengah meningkat 0,71 persen. Peningkatan pada periode tersebut lebih rendah jika dibandingkan dengan periode 2013-2014, yang naik sebesar 0,76 persen. Meskipun dari periode 2010-2015 IPM Jawa Tengah mengalami kemajuan yang besar, status pembangunan manusia di Jawa Tengah masih berstatus "sedang" [14]. Pada tahun 2017 IPM di Jawa Tengah mengalami peningkatan sebesar 0,54 persen yaitu 70,52 dibandingkan IPM Jawa 
Tengah pada tahun 2016. Pada tahun 2017, kualitas pembangunan manusia di Jawa Tengah mengalami peningkatan status dari level "sedang" menjadi level "tinggi" [15].

Tinggi rendahnya IPM kabupaten/kota di Provinsi Jawa Tengah hanya ditunjukkan melalui indeks komposit, tetapi tidak ditunjukkan indikator yang dominan terhadap tinggi rendahnya peringkat IPM, maka pengelompokan wilayah kabupaten/kota di Jawa Tengah juga perlu dilakukan sebagai bahan perencanaan dan evaluasi sasaran pemerintah [16]. Untuk mengatasi hal ini pemerintah memerlukan gambaran umum kondisi sosial ekonomi kabupaten/kota di Jawa Tengah dengan pengelompokkan di setiap bidang IPM. Salah satu metode yang dapat digunakan untuk pengelompokan variabel atau obyek adalah analisis cluster [17].

Penelitian tentang analisis cluster pernah dilakukan oleh Tahta Alfina tahun 2012 dengan judul "Analisa perbandingan Metode Hierarchical Clustering, K-means dan gabungan keduanya dalam Cluster Data dengan studi kasus "Problem Kerja Praktek Jurusan Teknik Industri ITS". Dalam penelitian ini data yang digunakan adalah data teks, dimana data ini merupakan data problem kerja praktek jurusan teknik industri ITS yang disampaikan oleh mahasiswa melalui forum diskusi jejaring sosial facebook. Metode yang digunakan adalah metode document clustering dengan $K$-means dan hierarchical clustering. K-means mempunyai kelemahan yang diakibatkan oleh penentuan pusat awal cluster. Hal ini menyebabkan hasil clusternya berupa solusi yang bersifat local optimal. Untuk itu, maka $k$-means dikolaborasikan oleh metode hierarki untuk penentuan pusat awal cluster. Dan hasil dari algoritma hierarchical clustering dan k-means menghasilkan pengelompokan data yang lebih baik jika dibandingankan dengan k-means dalam semua pengujian. Dengan evaluasi koefisian cophenetic, metode clustering terbaik dihasilkan oleh average linkage clustering. Dalam studi kasus Problem Kerja Praktek Jurusan Teknik Industri ITS, dari kombinasi hierarchical clustering dan $k$-means yang ada, kombinasi single linkage clustering dan k-means menghasilkan pengelompokan data yang terbaik dibandingan dengan metode hierarki yang lainnya.

Penelitian analisis cluster juga pernah dilakukan oleh Sarita Budiyani Purnamasari tahun 2014 dengan judul "Pemilihan Cluster Optimum pada Fuzzy C Means" dengan studi kasus "Kasus Pengelompokan Kabupaten/Kota di Provinsi Jawa Tengah berdasarkan Indikator Indeks Pembangunan Manusia". Dalam penelitian ini menggunakan formula jarak Manhattan dan Euclidean sebagai formula jarak pada analisis FCM yang akan digunakan dalam penelitian ini. Dalam pemilihan jarak menghasilkan kualitas pengelompokan terbaik dengan memperhatikan nilai simpangan bakunya ( $\operatorname{rasio} S_{\mathrm{w}} S_{\mathrm{b}}$ ). Penentuan jumlah cluster optimum pada jarak terpilih dilakukan dengan menggunakan perhitungan nilai validitas Xie Beni. Hasil yang didapat dari penelitian ini adalah jarak Euclidean memberikan kualitas ketepatan pengelompokan lebih baik dan jumlah cluster optimum diberikan saat jumlah cluster adalah lima dengan nilai Xie Beni terkecil dibanding cluster lainnya.

Metode Fuzzy C-Means sendiri memiliki kelemahan yaitu kurang tepatnya dalam pengelompokkan obyek [18]. Dalam perbandingan dengan metode Fuzzy C-Means kinerja ketepatan pengelompokan metode Latent Class Cluster Analysis (LCCA) lebih baik dan lebih cocok digunakan untuk penelitian fenomena sosial ekonomi yang memiliki indikator saling berkaitan [18]. Pada prinsipnya, LCCA juga tidak jauh berbeda dari metode $K$-Means yaitu pengelompokan sejumlah objek yang terdekat dengan pusat kelompok sehingga jarak setiap objek ke pusat kelompok dalam satu kelompok adalah minimum [19]. Perbedaannya yaitu K-Means penglompokkannya dengan pendekatan jarak sedangkan LCCA menggunakan konsep probabilitas [20]. Metode LCCA dapat menjadi ide terbaik sebagai perbaikan dari analisis klaster, dimana LCCA menggunakan konsep statistic likelihood dan peluangnya berdasarkan nilai statistik Bayesian Information Criterion (BIC) [19].

Penelitian LCCA pernah dilakukan oleh Nurhayati pada tahun 2015 dengan judul "Pengelompokan Pasien Demam Berdarah RSUD dr. Soehadi Prijonegoro dengan Metode Analisis Kelas Laten". Hasil dari analisis ini adalah terdapat dua kelas yang terbentuk yaitu kelas 0 dan kelas 1 . Pasien pada kelas 0 memiliki kriteria penyakit infeksi dengue dengan tanda bahaya yaitu hasil pemeriksaan hematocrit yang normal, leukosit yang tidak normal serta trombosit tidak normal. Pasien pada kelas 1 memiliki kriteria penyakit infeksi dengue tanpa tanda bahaya yaitu hasil pemeriksaan hematocrit yang normal, leukosit yang normal serta trombosit yang normal.

Berdasarkan uraian di atas, peneliti ingin mengetahui gambaran umum kabupaten/kota di Jawa Tengah berdasarkan indikator Indeks Pembangunan Manusia 2017 dan menggunakan metode LCCA untuk pengelompokan kabupaten/kota di Provinsi Jawa Tengah berdasarkan indikator indeks pembangunan manusia 2017 serta ciri-ciri dari setiap kelompok. 


\section{METODOLOGI}

\subsection{Sumber dan Jenis Data}

Sumber data yang digunakan dalam analisis ini adalah data sekunder, yaitu data yang diperoleh secara tidak langsung atau melalui perantara, yaitu data indikator Indeks Pembangunan Manusia (IPM) kabupaten/kota di Provinsi Jawa Tengah yang dipublikasikan oleh BPS Jawa Tengah 2017.

\subsection{Variabel Penelitian}

Variabel yang digunakan dalam penelitian ini adalah indikator Indeks Pembangunan Manusia (IPM) Provinsi Jawa Tengah pada tahun 2017.

Tabel 1. Variabel Penelitian

\begin{tabular}{|c|l|c|}
\hline Variabel & \multicolumn{1}{|c|}{ Keterangan } & Skala Data \\
\hline $\mathrm{X}_{1}$ & Harapan Lama Sekolah & Rasio \\
\hline $\mathrm{X}_{2}$ & Angka Partisipasi Kasar & Rasio \\
\hline $\mathrm{X}_{3}$ & Angka Partisipasi Murni & Rasio \\
\hline $\mathrm{X}_{4}$ & Angka Partisipasi Sekolah & Rasio \\
\hline $\mathrm{X}_{5}$ & Rata-rata Lama Sekolah & Rasio \\
\hline $\mathrm{X}_{6}$ & Harapan Hidup saat Lahir & Rasio \\
\hline $\mathrm{X}_{7}$ & Tingkat Partisipasi Kerja & Rasio \\
\hline $\mathrm{X}_{8}$ & Tingkat Pengangguran Terbuka & Rasio \\
\hline $\mathrm{X}_{9}$ & Pengeluaran Per Kapita (dalam juta) & Rasio \\
\hline $\mathrm{X}_{10}$ & Angka Penduduk Miskin & Rasio \\
\hline $\mathrm{X}_{11}$ & Angka Putus Sekolah & Rasio \\
\hline $\mathrm{X}_{12}$ & Angka Kesakitan & Rasio \\
\hline $\mathrm{X}_{13}$ & Rata-rata Lama Sakit & Rasio \\
\hline $\mathrm{X}_{14}$ & Angka Kematian Balita & Rasio \\
\hline
\end{tabular}

\subsection{Metode Analisis Data}

\section{Analisis Cluster}

LCCA merupakan suatu model yang menghubungkan sejumlah variabel indikator yang bersifat kontinu dengan variabel laten kategorik yang dibentuknya [18]. Variabel laten adalah variabel yang tidak teramati atau variabel yang tidak dapat diukur secara langsung [21]. Analisis ini pertama kali diperkenalkan oleh Lazarfeld dan Henry pada tahun 1968 untuk pengelompokan berdasarkan variabel dikotomus, kemudian diperluas untuk variabel bertipe nominal oleh Goodman pada tahun 1974, dalam perkembangannya analisis ini dapat digunakan untuk pengelompokan objek pada variabel kategorik, kontinu, dan campuran [22].

Model LCCA didefinisikan sebagai rumus [20]:

dengan:

$$
f\left(\boldsymbol{x}_{\boldsymbol{h}} \mid \theta\right)=\sum_{j=1}^{c} \eta_{j} g\left(\boldsymbol{x}_{\boldsymbol{h}} \mid \theta\right),
$$

$$
\begin{array}{ll}
j & : \text { banyaknya kelas }(1,2, \ldots, \mathrm{c}), \mathrm{c} \epsilon \text { bilangan asli } \\
\eta_{j} & : \text { peluang prior (awal) kelas ke- } j \\
g\left(\boldsymbol{x}_{\boldsymbol{h}} \mid \theta\right) \quad: & \text { fungsi gabungan berupa fungsi kepadatan peluang dari setiap variabel yang digunakan }
\end{array}
$$

Tahapan estimasi parameter dilakukan dengan algoritma Expectation-Maximation (EM) yaitu algoritma partitional yang berbasiskan model yang menggunakan perhitungan probabilitas, tahapan algoritma EM yaitu [23]:

a. E-Step digunakan untuk mencari suatu ekspektasi dari fungsi log likelihood dengan rumus:

$$
Q=E\left[\log [L(\theta)] \mid x_{h}, \hat{\theta}^{(r-1)}\right] .
$$


M-Step digunakan untuk mencari nilai taksiran parameter yang didefinisikan pada E-Step untuk memaksimumkan fungsi log likelihood.

$$
\begin{gathered}
\hat{\eta}_{j}=\sum_{h=1}^{n} \frac{p\left(j \mid x_{h}, \hat{\eta}_{j}^{(r-1)}, \hat{\mu}_{i j}{ }^{(r-1)}, \hat{\sigma}_{i j}{ }^{(r-1)}\right.}{n} \\
g \hat{\mu}_{i j}=\frac{\sum_{h=1}^{n} x_{i h} p\left(j \mid x_{h}, \hat{\eta}_{j}^{(r-1)}, \hat{\mu}_{i j}{ }^{(r-1)}, \hat{\sigma}_{i j}{ }^{(r-1)}\right.}{n \hat{\eta}_{j}^{(r)}} \\
\hat{\sigma}_{i j}{ }^{2(r)}=\frac{\sum_{h=1}^{n} \sum_{j=1}^{c}\left(x_{i h}-\hat{\mu}_{i j}{ }^{(r-1)}\right)^{2} p\left(j \mid x_{h}, \hat{\eta}_{j}{ }^{(r-1)}, \hat{\mu}_{i j}{ }^{(r-1)}, \hat{\sigma}_{i j}{ }^{(r-1)}\right.}{\sum_{h=1}^{n} \sum_{j=1}^{c} p\left(j \mid x_{h}, \hat{\eta}_{j}{ }^{(r-1)}, \hat{\mu}_{i j}{ }^{(r-1)}, \hat{\sigma}_{i j}{ }^{(r-1)}\right.}
\end{gathered}
$$

Kedua langkah dilakukan terus menerus hingga mencapai nilai konvergen. Selanjutnya digunakan metode Newton-Raphson untuk memaksimumkan nilai taksiaran tersebut.

b. Memilih kelompok terbaik dengan melihat nilai BIC terkecil dari model yang telah dicoba. Rumus BIC

$$
\mathrm{BIC}_{\mathrm{LL}}=-2 \mathrm{LL}+\ln (\mathrm{N}) \mathrm{M} \text {, }
$$

dengan:

$\mathrm{N}$ = Banyaknya objek pengamatan

$\mathrm{M}=$ Jumlah Parameter

$\mathrm{LL}=$ Nilai likelihood yang telah optimum.

Setelah diperoleh model terbaik, langkah selajutnya pengelompokan objek ke dalam cluster yang dilakukan dengan menghitung peluang posterior dari masing-masing objek terhadap cluster yang terbentuk dengan rumus [20]:

$$
P\left(j \mid \boldsymbol{x}_{\boldsymbol{h}}, \widehat{\theta}\right)=\frac{\hat{\eta}_{j} g\left(\boldsymbol{x}_{\boldsymbol{h}} \mid \widehat{\theta}\right)}{\sum_{j=1}^{c} \hat{\eta}_{j} g\left(\boldsymbol{x}_{\boldsymbol{h}} \mid \widehat{\theta}\right)} .
$$

Pemilihan anggota dari suatu cluster dilakukan dengan melihat peluang posterior tertinggi dari suatu objek untuk setiap cluster-nya. Selanjutnya dilakukan interpretasi untuk masing-masing cluster yang terbentuk.

\section{HASIL DAN PEMBAHASAN}

Dari hasil analisis didapatkan 5 cluster yaitu 1 cluster dengan nilai 2822.875, 2 cluster dengan nilai 2666,668, 3 cluster dengan nilai 2698,076, 4 cluster dengan nilai 2745,951 dan 5 cluster dengan nilai 2781,869 dari 5 cluster yang didapatkan dipilih nilai BIC terkecil guna memilih model terbaik.

Tabel 2. Nilai BIC

\begin{tabular}{|cccccc|}
\hline $\begin{array}{c}\text { Nbr } \\
\text { Clusters }\end{array}$ & LL & BIC(LL) & AIC(LL) & AIC3(LL) & $\begin{array}{c}\text { Number of } \\
\text { parameters }\end{array}$ \\
\hline 1 & -1361.66 & 2822.875 & 2779.325 & 2807.32 & 28 \\
2 & -1232.00 & $\mathbf{2 6 6 6 . 6 6 8}$ & 2578.014 & 2635.01 & 57 \\
3 & -1196.15 & 2698.076 & 2564.316 & 2650.31 & 86 \\
4 & -1168.54 & 2745.951 & 2567.086 & 2682.08 & 115 \\
5 & -1134.94 & 2781.869 & 2557.899 & 2701.89 & 144 \\
\hline
\end{tabular}

Berdasarkan Tabel 2, dapat dilihat bahwa 2 cluster memiliki nilai BIC terkecil yaitu sebesar 2666.668, maka cluster yang digunakan yaitu 2 cluster. Setelah mendapatkan jumlah cluster yaitu 2 cluster selanjutnya yaitu membentuk karakteristik 2 cluster dan menamai cluster tersebut. Pembagian karakteristik cluster dapat dilihat dari proflil cluster yang benilai maksimum untuk Harapan Lama Sekolah, Angka Partisipasi Murni, Rata-rata Lama Sekolah, Angka Harapan Hidup saat Lahir, Tingkat Partisipasi Angkatan Kerja, Angka Partisipasi Kasar, Angka Partisipasi Sekolah, dan bernilai minimum untuk Pengeluaran Perkapita, Tingkat 
Pengangguran Terbuka, Angka Penduduk Kemiskinan, Angka Kesakitan, Angka Putus Sekolah, Rata-rata Lama Sakit dan Angka Kematian Bayi. Tidak ada kriteria khusus dalam penamaan 2 cluster tersebut, karena hanya terdapat 2 cluster maka dibagi menjadi cluster IPM tinggi dan cluster IPM rendah. Kriteria cluster IPM tinggi yaitu cluster yang memiliki variabel yang lebih banyak yang sesuai dengan karakteristik dari profil cluster dibandingkan dengan cluster IPM rendah. Berdasarkan Tabel 3 disimpulkan bahwa karakteristik dari cluster 1 terdiri dari variabel $\mathrm{X}_{2}, \mathrm{X}_{4}, \mathrm{X}_{7}, \mathrm{X}_{9}$, dan $\mathrm{X}_{14}$, kemudian karakteristik dari cluster 2 terdiri dari $\mathrm{X}_{1}, \mathrm{X}_{3}, \mathrm{X}_{5}, \mathrm{X}_{6}, \mathrm{X}_{8}, \mathrm{X}_{10}, \mathrm{X}_{11}, \mathrm{X}_{12}$, dan $\mathrm{X}_{13}$

Tabel 3. Profile Cluster

\begin{tabular}{ccrr}
\hline Variables & Categories & Cluster1 & \multicolumn{1}{c}{ Cluster2 } \\
\hline Cluster size & & 0.764 & 0.236 \\
\hline $\mathrm{X}_{1}$ & $\mathrm{HLS}$ & 12.349 & $\mathbf{1 3 . 9 5 1}$ \\
\hline $\mathrm{X}_{2}$ & $\mathrm{APK}$ & $\mathbf{1 0 8 . 6 3 1}$ & 103.577 \\
\hline $\mathrm{X}_{3}$ & $\mathrm{APM}$ & 96.963 & $\mathbf{9 7 . 9 4 0}$ \\
\hline $\mathrm{X}_{4}$ & $\mathrm{APS}$ & $\mathbf{9 9 . 6 1 8}$ & 91.191 \\
\hline $\mathrm{X}_{5}$ & $\mathrm{RLS}$ & 7.036 & $\mathbf{9 . 4 2 4}$ \\
\hline $\mathrm{X}_{6}$ & $\mathrm{AHHL}$ & 74.110 & $\mathbf{7 6 . 3 9 1}$ \\
\hline $\mathrm{X}_{7}$ & PPK & $\mathbf{9 7 7 5 . 7 8 4}$ & 12568.795 \\
\hline $\mathrm{X}_{8}$ & TPAK & 69.484 & $\mathbf{6 8 . 1 1 9}$ \\
\hline $\mathrm{X}_{9}$ & $\mathrm{TPT}$ & $\mathbf{4 . 3 8 4}$ & 5.051 \\
\hline $\mathrm{X}_{10}$ & APKm & 13.759 & $\mathbf{8 . 2 1 2}$ \\
\hline $\mathrm{X}_{11}$ & $\mathrm{AKs}$ & 16.452 & $\mathbf{1 2 . 8 9 6}$ \\
\hline $\mathrm{X}_{12}$ & APSe & 75.137 & $\mathbf{6 0 . 1 4 1}$ \\
\hline $\mathrm{X}_{13}$ & $\mathrm{RLSk}$ & 5.767 & $\mathbf{5 . 5 9 3}$ \\
\hline $\mathrm{X}_{14}$ & AKB & $\mathbf{1 0 . 9 6 3}$ & 11.587 \\
\hline & & &
\end{tabular}

Berdasarkan analisis karakteristik anggota cluster, maka kabupaten/kota anggota untuk masing-masing cluster dapat dilihat pada Tabel 4.

Tabel 4. Classification Cluster

\begin{tabular}{|l|c|}
\hline \multicolumn{1}{|c|}{ Kabupaten/Kota } & Cluster \\
\hline Kab_Cilacap & 1 \\
\hline Kab_Banyumas & 1 \\
\hline Kab_Purbalingga & 1 \\
\hline Kab_Banjarnegara & 1 \\
\hline Kab_Kebumen & 1 \\
\hline Kab_Purworejo & 1 \\
\hline Kab_Wonosobo & 1 \\
\hline Kab_Magelang & 1 \\
\hline Kab_Boyolali & 1 \\
\hline Kab_Klaten & 1 \\
\hline Kab_Sukoharjo & 2 \\
\hline Kab_Wonogiri & 1 \\
\hline Kab_Karanganyar & 2 \\
\hline Kab_Sragen & 1 \\
\hline Kab_Grobogan & 1 \\
\hline Kab_Blora & 1 \\
\hline Kab_Rembang & 1 \\
\hline Kab_Pati & 1 \\
\hline Kab_Kudus & 1 \\
\hline Kab_Jepara & 1 \\
\hline Kab_Demak & 1 \\
\hline Kab_Semarang & 1 \\
\hline Kab_Temanggung & 1 \\
\hline Kab_Kendal & 1 \\
\hline Kab_Batang & 1 \\
\hline Kab_Pekalongan & 1 \\
\hline
\end{tabular}




\begin{tabular}{|l|l|}
\hline Kab_Pemalang & 1 \\
\hline Kab_Tegal & 1 \\
\hline Kab_Brebes & 1 \\
\hline Kota_Magelang & 2 \\
\hline Kota_Surakarta & 2 \\
\hline Kota_Salatiga & 2 \\
\hline Kota_Semarang & 2 \\
\hline Kota_Pekalongan & 2 \\
\hline Kota_Tegal & 2 \\
\hline
\end{tabular}

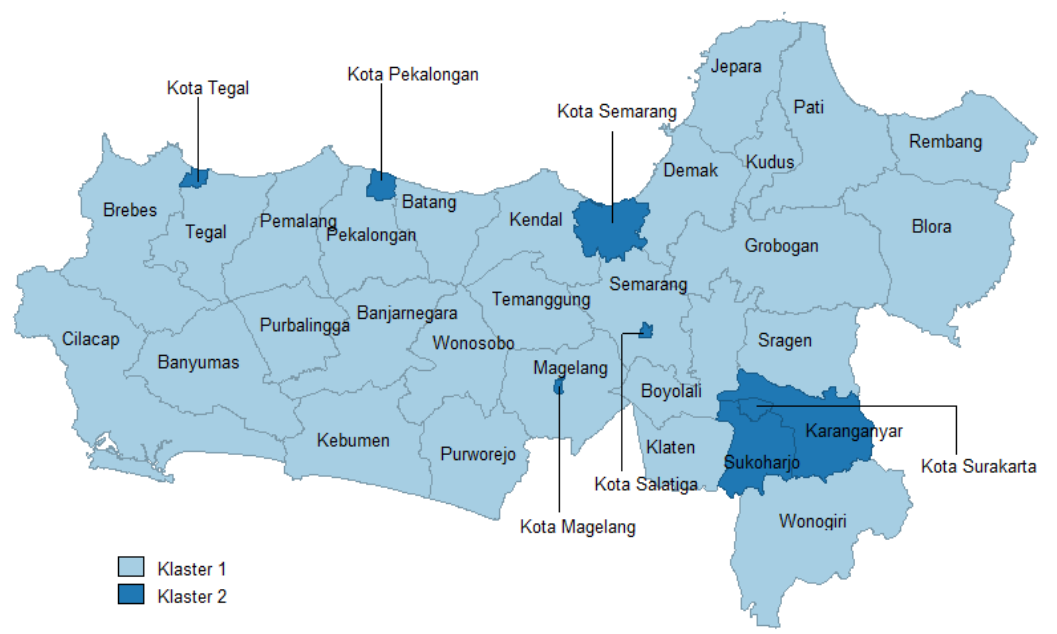

Gambar 1. Peta Persebaran Cluster

Berdasarkan Tabel 4 dan Gambar 1, dapat disimpulkan bahwa anggota cluster sebagai berikut:

Cluster 1: Kabupaten Cilacap, Kabupaten Banyumas, Kabupaten Purbalingga, Kabupaten Banjarnegara, Kabupaten Kebumen, Kabupaten Purworejo, Kabupaten Wonosobo, Kabupaten Magelang, Kabupaten Boyolali, Kabupaten Klaten, Kabupaten Wonogiri, Kabupaten Sragen, Kabupaten Grobogan, Kabupaten Blora, Kabupaten Rembang, Kabupaten Pati, Kabupaten Kudus, Kabupaten Jepara, Kabupaten Demak, Kabupaten Semarang, Kabupaten Temanggung, Kabupaten Kendal, Kabupaten Batang, Kabupaten Pekalongan, Kabupaten Pemalang, Kabupaten Tegal, Kabupaten Brebes.

Cluster 2 : Kabupaten Sukoharjo, Kabupaten Karanganyar, Kota Magelang, Kota Surakarta, Kota Salatiga, Kota Semarang, Kota Pekalongan, Kota Tegal.

\section{KESIMPULAN}

a. Karakteristik dari setiap kelompok kabupaten/kota berdasarkan data indikator indeks pembangunan manusia 2017:

- Cluster 1: Kelompok ini beranggotakan 27 kabupaten dengan melihat aspek Angka Partisipasi Kasar, Angka Partisipasi Sekolah, Pengeluaran Perkapita, Tingkat Pengangguran Terbuka dan Angka Kematian Bayi

- Cluster 2: Kelompok ini beranggotakan 8 kabupaten/kota dengan melihat aspek Harapan Lama Sekolah, Angka Partisipasi Murni, Rata-rata Lama Sekolah, Angka Harapan Hidup saat Lahir, Tingkat Partisipasi Angkatan Kerja, Angka Penduduk Kemiskinan, Angka Kesakitan, Angka Putus Sekolah, Rata-rata Lama Sakit.

b. Berdasarkan pengelompokkan tersebut cluster 2 merupakan "IPM tinggi" karena terdapat lebih banyak variabel 9 variabel diantaranya kesehatan dan Pendidikan terbanyak, kemudian kelompok 1 merupakan "IPM rendah" karena terdapat 5 variabel diantaranya dalam komponen kesehatan hanya terdapat 1 variabel dan 2 variabel Pendidikan. 


\section{DAFTAR PUSTAKA}

[1] Melliana, A., \& Zain, I., "Analisis Statistika Faktor yang Mempengaruhi Indeks Pembangunan Manusia di Kabupaten/Kota Provinsi Jawa Timur dengan Menggunakan Regresi Panel”, Jurnal Sains Dan Seni ITS, Vol.2, No.2, pp.237-242, [Online]. http://ejurnal.its.ac.id/index.php/sains seni/article/view/4844 [Diakses 2 Juli 2019].

[2] Sanggelorang, S., Rumate, V., \& Siwu, H., "Pengaruh Penegluaran Pemerintah di Sektor Pendidikan dan Kesehatan terhadap Indeks Pembangunan Manusia di Sulawesi Utara”, Jurnal Berkala Ilmiah Efesiensi, vol.15, No.2, pp.1-11,2015.

[3] TAP MPR No. IV/MPR/1999., tentang GBHN 1999-2004,1999.

[4] Chalid, N \& Yusuf, Y., "Pengaruh Tingkat Kemiskinan dan Tingkat Pengangguran, Upah Minimun Kabupaten/Kota Dan Laju Pertumbuhan Ekonomi Terhadap Indeks Pembangunan Manusia di Provinsi Riau", Jurnal Ekonomi, Vol.22, No.2, pp.1-12, [Online]. Tersedia http://ejournal.unri.ac.id/index.php/JE/article/viewFile/2592/2547\%0A [Diakses 2 Juli 2019].

[5] Badan Perencanaan Pembangunan Nasional. Rencana aksi nasional pangan dan gizi 2011-2015,2011.

[6] Maqin, A., "Indeks Pembangunan Manusia" : Tinjauan Teoritis dan Empiris di Jawa Barat, Bandung: 2008, pp.1-23.

[7] Pratomo, D., \& Sumargo, B., "Sebuah Alternatif: Better Life Index sebagai Ukuran Pembangunan Multidimensi di Indonesia" An Alternative: Better Life Index as a Measure of Multidimensional Development in Indonesia Pendahuluan. Vol.16, No.2, pp.123-140,2017.

[8] Bhakti, N. A., Istiqomah, \& Suprapto, "Analisis Faktor-Faktor yang Mempengaruhi Indeks Pembangunan Manusia di Indonesia Periode 2008-2012”, Jurnal Ekonomi Dan Keuangan, Vol.14, No.4, pp.452-469, 2012.

[9] Setiawan, M. B., \& Hakim, A., "Indeks Pembangunan Manusia Indonesia", Jurnal Economia, Vol.9, No.1, pp.18-26. [Online]. Tersedia https://media.neliti.com/media/publications/19711-ID-indekspembangunan-manusia-indonesia.pdf [Diakses 2 Juli 2019].

[10] [BPS] Badan Pusat Statistik Indonesia, "Indeks Pembangunan Manusia Tahun 2015", Berita Resmi Statistik, vol.57, pp.1-8,2016.

[11] [BPS] Badan Pusat Statistik Indonesia, "Indeks Pembangunan Manusia Tahun 2016”, Vol.37, pp.1-8, 2017.

[12] [BPS] Badan Pusat Statistik Indonesia, “Indeks Pembangunan Manusia 2017" Badan Pusat Statistik, Vol.33, pp.1-8, 2018.

[13] [BPS] Badan Pusat Statistik Kabupaten Sekadau, "Indeks Pembangunan Manusia (IPM) Kabupaten Sekadau 2015”, no.04/10/6109/Th.II, pp.1-7. 2016.

[14] [BPS] Badan Pusat Statistik Jateng, “Indeks Pembangunan Manusia 2015”, Vol.42, pp.1-7, 2016.

[15] [BPS] Badan Pusat Statistik Jateng, "Indeks Pembangunan Manusia 2017”, Vol.07, pp.1-6, 2018.

[16] Purnamasari, S. B., "Pemilihan Cluster Optimum pada Fuzzy C Menas (Studi Kasus Pengelompokan Kabupaten/Kota di Provinsi Jawa Tengah Berdasarkan Indikator Indeks Pembangunan manusia)", Jurnal Gaussian, Vol.3, No.3, pp.491-498,2014.

[17] Putri, R., \& Widodo, E., “Analisis Klaster Hierarki Untuk Pengelompokkan Kabupaten / Kota Di Jawa Tengah Berdsarkan Indikator Indeks Pembangunan Manusia ( IPM ) Tahun 2015”,Vol.1, No.1, pp.229$239,2017$.

[18] Gustiana, Y. Y., Suwanda, \& Zulhanif., "Perbandingan Fuzzy C-Means Clustering dengan Latent Class Clustering Analysis". 1, pp.1-37,2009.

[19] Chadidjah, A., Seminar Nasional Pendidikan Matematika 2016, pp.1-11,2016. 
[20] Vermunt, J. K., \& Magidson, J., "Latent Class Cluster Analysis”, Applied Latent Class Analysis, pp.89106, [Online].Tersedia https://doi.org/10.1017/cbo9780511499531.004 [Diakses 2 Juli 2019].

[21] Nurhayati, N., Mukid, M. A., \& Ispriyanti, D., "Pengelompokan Pasien Demam Berdarah Rsud Dr.Soehadi Prijonegoro Dengan Metode Analisis Kelas Latin", Vol.4, pp.93-102,2015.

[22] Budiati, S., Susanto, I., \& Wibowo, S., "Pengelompokan Daerah Penghasil Bahan Dasar Tepung Komposit Di Indonesia Menggunakan Metode Latent Class Cluster Analysis (LCCA)", Media Statistika, Vol.7, No.1, pp.21-28, [Online]. Tersedia https://doi.org/10.14710/medstat [Diakses 2 Juli 2019].

[23] Hafizha, Z. R., Rachmatin, D., \& Puspita, E., "Pengelompokan Kecamatan Di Kabupaten Bandung Berdasarkan Indikator Kemiskinan Tahun 2015 Menggunakan Metode Latent Class Cluster Analysis (LCCA)", Jurnal EurekaMatika, Vol.6, No.2, pp.83-93,2018. 